\title{
Generalized FAST approach for seismic assessment of infilled RC MRF buildings: application to the 2011 Lorca earthquake
}

\author{
F. Gómez-Martínez ${ }^{1}$ A. Pérez-García ${ }^{1}$, F. De Luca ${ }^{2}$ \\ \& G. M. Verderame ${ }^{2}$ \\ ${ }^{I}$ Department of Mechanics of the Continuum Media and Structural \\ Theory, Polytechnic University of Valencia, Spain \\ ${ }^{2}$ Department of Structures for Engineering and Architecture, DIST, \\ University of Naples Federico II, Italy
}

\begin{abstract}
A generalized formulation of FAST vulnerability method for Reinforced Concrete Moment Resisting Frame (RC-MRF) buildings with non-uniform distribution of masonry infills in elevation is presented. This method belongs to the wider family of spectral-based methodologies. It was already proposed for uniformly infilled frames, and then applied to different earthquakes for benchmarking purposes. The new generalized approach allows us to consider a reduction of the amount of infills at the ground floor. Thus, this new version of FAST is capable of computing all intermediate situations between the opposite cases: uniformly infilled and pilotis (no infills at ground storey) MRF. Finally, this generalized FAST method is applied to the case of the Lorca (Spain) 2011 earthquake, using parameters according to the local construction practice of the area. Results show a fair agreement with damage survey data.
\end{abstract}

Keywords: infilled RC-MRF, pilotis, period, damage states, Lorca earthquake, FAST.

\section{Introduction}

In previous studies (De Luca et al. [1], Manfredi et al. [2]), a simplified approach (FAST) for the estimation of large-scale vulnerability of uniformly infilled Reinforced Concrete Moment Resisting Frames (RC-MRF) has been 
carried out, and tested by means of the employment of post-earthquake damage data as a benchmark. The aim of this study is to provide a generalized form of the method that includes non-uniformly infilled frames; in particular, infilled frames with a reduction of the amount of infills at the ground floor. This configuration is quite frequent for residential building practice in the Mediterranean area. In section 2, basic principles of the original method are described and its generalization is presented in detail. In section 3 the new approach is applied to the case of Lorca (Spain) 2011 earthquake. Finally, comparisons of the analytical results of FAST with damage survey data are shown.

\section{FAST vulnerability approach}

FAST approach provides information about the vulnerability in terms of damage state (DS) of infilled RC-MRF, allowing a preliminary comparison with observed damage. Necessary data for its implementation are: (i) number of storeys (n), (ii) age of construction, and (iii) location of the building or set of buildings considered. All those information are necessary for the definition of the capacity curves of the buildings, while information (iii) is also necessary for demand characterization (e.g., PGA demand).

\subsection{Basic concepts}

FAST is based on a simplified definition of the capacity curve (CC) of infilled buildings and an approximate mechanical interpretation of damage states (DS) of the EMS-98 scale. Once defined the CC, the corresponding IN2 curve (Dolšek and Fajfar [3]) in terms of PGA for the equivalent Single Degree of Freedom (SDOF) is obtained. Then, thanks to an empirical-mechanical interpretation of the DS in terms of interstorey drift (IDR) at first storey, top displacement thresholds of the SDOF, corresponding to each DS, are carried out. The IN2 curve allows the switch from SDOF displacement thresholds to PGA characterizing the exceedance of each DS. Thus, given an earthquake, it is possible to estimate which is the average DS expected for each class of building.

\subsubsection{Capacity curve}

The simplified CC (Dolšek and Fajfar [3]) (Figure 1) asks for the definition of:

- $\quad C_{s, \max }$ and $C_{s, \min }$ : maximum and minimum (residual) inelastic spectral acceleration capacity, both obtained (eqn (1)) as weighted addition of the respective capacities of bare frame, $C_{s, R C}$, and infills, $C_{s, w}$ (eqn (2)).

- $\quad \mu_{\mathrm{s}}$ : available ductility up to the beginning of the degradation of the infills, assumed to be 2.5 (Manfredi et al. [4]).

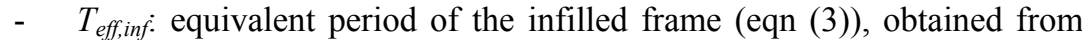
the elastic one through factor $\kappa$ assumed to be 1.4 (Ricci et al. [5]).

The rest of the necessary variables can be divided in four groups:

1) Assessment parameters: $\alpha=0.5$ and $\beta=0.0$; they weight the contribution of $\mathrm{RC}$ and infills, at the maximum and residual part of the curve, respectively. 
$R_{\omega}(=1.45)$ and $R_{\alpha}(=1.00)$, the overstrength factors of material (Galasso et al. [6]) and structural redundancy, respectively. Finally, $m_{r}$, the average storey superficial mass, assumed equal at each storey; and $\tau_{\max }$, maximum infills shear resistance corresponding to the attainment of a diagonal strut mechanism.

2) Code parameters: $S_{a}(T)$, spectral design acceleration; $m_{d}$, average design storey superficial mass assumed equal at each storey; $\lambda_{d}$, design ratio of first mode participating mass with respect to the total one for the MDOF; and $\gamma_{d}$, design seismic combination factor.

3) Dynamic parameters: $\left(\mathrm{m}^{*} / \mathrm{M}\right)$, ratio of first mode participating mass against the total one of the SDOF; $\Gamma$, first mode participating factor; and $\left(K_{g} / A_{b}\right)$, the global elastic stiffness of the structure, normalized by the area of the building.

4) Building parameters: $n$, number of storeys; $\rho_{w, 1}$, ground floor ratio between the effective area of infills in each direction with respect to the building area, $A_{b}$.

$$
\begin{array}{cc}
C_{s, \text { max }}=\alpha \cdot C_{s, R C}+C_{s, w} ; & C_{s, \text { min }}=C_{s, R C}+\beta \cdot C_{s, w} \\
C_{s, R C}=S_{a}(T) \frac{m_{d}}{m_{r}} \frac{\lambda_{d} \gamma_{d}}{\Gamma\left(\frac{m^{*}}{M}\right)} R_{\omega} R_{\alpha} ; & C_{s, w}=\frac{\tau_{\max }}{m_{r}} \frac{\rho_{w, 1}}{\Gamma\left(\frac{m^{*}}{M}\right)^{*}} \frac{1}{n} \\
T_{e f f \text {, inf }}=\kappa \cdot T_{e l \text {, nf }}=\kappa \cdot 2 \pi \sqrt{\left(\frac{m^{*}}{M}\right) \frac{m_{r}}{\left(K_{g} / A_{b}\right)}} \sqrt{n}
\end{array}
$$

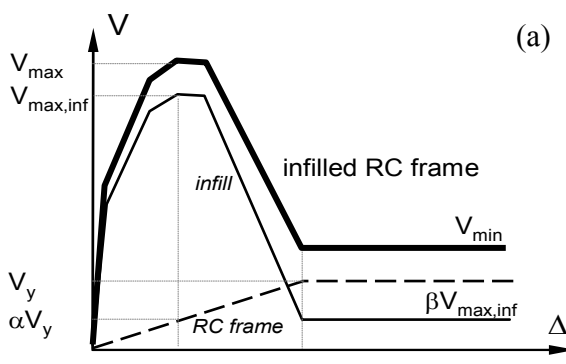

(a)

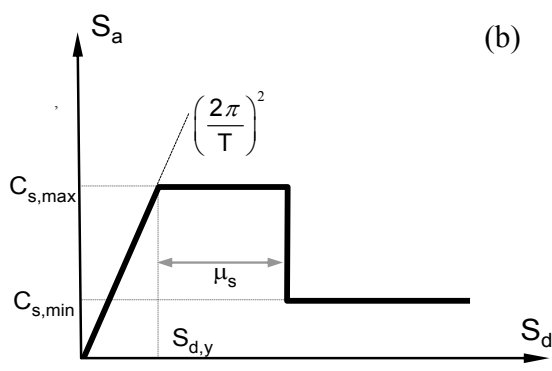

Figure 1: Infilled RC-MRF pushover curve (a) and its idealization in Acceleration Displacement Response Spectrum format (b).

\subsubsection{DS interpretation}

SDOF spectral displacement for each DSj $(1 \leq j \leq 3), S_{d \mid D S j}$ (eqn (4)), is obtained considering a shear-type frame with no deformation of the beams. In order to obtain an approximated resolution of the dynamic problem, based on Rayleigh method, the algorithm asks for the assumption of a load pattern of the seismic forces that results in elastic displacements proportional to them, given the assumption of identical masses at each storey. This load pattern increases in homothetic way to obtain the different DS. The top displacement, $d_{n \mid D S j}$, is evaluated as the sum of first storey displacement, where the corresponding DS is attained, and the smaller contribution of the rest of the building according to 
its different elastic stiffness, shear forces and stiffness degradation. Three reduction factors account for these differences, being $i$ the identifier of each storey:

- $\quad \chi$ represents the ratio between the elastic stiffness at ground floor with respect to the average one of the rest of the storeys, due to the typical ground floor's higher interstorey height and lower infills ratio. Upper stiffnesses are equal between each other, as the method requires upper storeys to have the same interstorey height and amount of infills.

- $\quad \zeta$ represents the ratio between the average shear force in the upper storeys and the base shear; it is independent of the DSj, as the shear force pattern increases homothetically.

- $\quad \gamma$ represents the ratio between the secant post-cracking stiffness at ground floor when DS2 is attained and the average equivalent secant stiffness at the upper floors. The progressive degradation of the stiffness is represented by a factor $\Omega_{i}$ that varies between 1.00 in the storeys without cracking and an approximate value of $\Omega_{s e c}=0.25$ (Colangelo [7]) for the maximum degradation at the attainment of the DS2.

The interstorey drift thresholds $\left(I D R_{D S j}\right)$ assume values of $0.03 \%, 0.2 \%$ and $1.2 \%$ for DS1, DS2 and DS3, respectively (De Luca et al. [1], Manfredi et al. [2]); $h_{1}$ and $h_{s}$ are the interstorey heights of the ground and upper storeys, respectively.

$$
S_{d \mid D S 1}=\frac{d_{n \mid D S j}}{\Gamma} ; \quad d_{n \mid D S j}=\left\{\begin{array}{ll}
d_{n \mid D S 1}=I D R_{D S 1} \cdot h_{1}[1+\chi \cdot \zeta \cdot(n-1)] & , j=1 \\
d_{n \mid D S 2}=I D R_{D S 2} \cdot h_{1}[1+\chi \cdot \zeta \cdot \gamma \cdot(n-1)], j=2 \\
d_{n \mid D S 3}=d_{n \mid D S 2}+h_{1}\left(I D R_{D S 3}-I D R_{D S 2}\right) & , j=3
\end{array}\right\}
$$

\subsection{Generalization of the method: non-uniformly infilled RC MRF}

Infilled RC-MRF with a substantial reduction or even inexistence of infills at ground floor are usually called pilotis frames. In FAST approach, this situation is represented by a lower value of $\chi$ if compared with uniformly infilled frames $(\chi \approx 1.0)$. It is worth noting that all the intermediate situations from uniformly infilled to pilotis frames are susceptible to be considered since $\chi$ can take any value between $1 \leq \chi<0$. Expressions for required parameters $\chi, \zeta, \gamma,\left(m^{*} / M\right), \Gamma$, $\left(K_{g} / A_{b}\right)$ are developed for both cases. The formulae corresponding to the parameters described in subsections 2.2.2 to 2.2.5 can be found in the Appendix.

\subsubsection{Definition of the irregularity of stiffness}

The factor $\chi$ depends on the ratio of stiffness at ground and upper storeys, both normalized by the building area $A_{b}$. The stiffness of the $i^{\text {th }}$ storey is approximately the sum of the contribution of the infills' shear stiffness $\left(K_{w, i}\right)$ and that of the RC columns $\left(K_{R C, i}\right)$. The first one can be expressed (eqn (5a)) as function of the infills' area ratio $\left(\rho_{w, i}\right)$, the shear modulus $\left(G_{w}\right)$ and the interstorey height; while the second one (eqn (5b)), assuming a square section for the columns, depends on the Young modulus $\left(E_{c}\right)$, the dimension of the columns section $\left(b_{c}\right)$, the tributary area of loads for each column $\left(A_{t r i b}\right)$ and the interstorey 
height. Therefore, $\chi$ is expressed (eqn (6a)) as function of the ratios of interstorey heights and infills areas between ground and upper storeys, multiplied by a factor $c_{\chi}$ (eqn (6b)) which accounts for the contribution of the RC only in the ground floor, as for upper storeys it may be neglected (see section 3.2.2).

$$
\begin{array}{cc}
K_{w, i} / A_{b}=\frac{G_{w} \rho_{w, i}}{h_{\mathrm{i}}} ; & K_{R C, i} / A_{b}=\frac{E_{c} b_{c, i}^{4}}{A_{t r i b} h_{i}{ }^{3}} \\
\chi \approx \frac{K_{w, 1}+K_{R C, 1}}{K_{w, s}}=\left(1+c_{\chi}\right) \frac{\rho_{w, 1}}{\rho_{w, s}} \frac{h_{s}}{h_{1}} ; & c_{\chi}=\frac{K_{R C, 1} / A_{b}}{K_{w, 1} / A_{b}}
\end{array}
$$

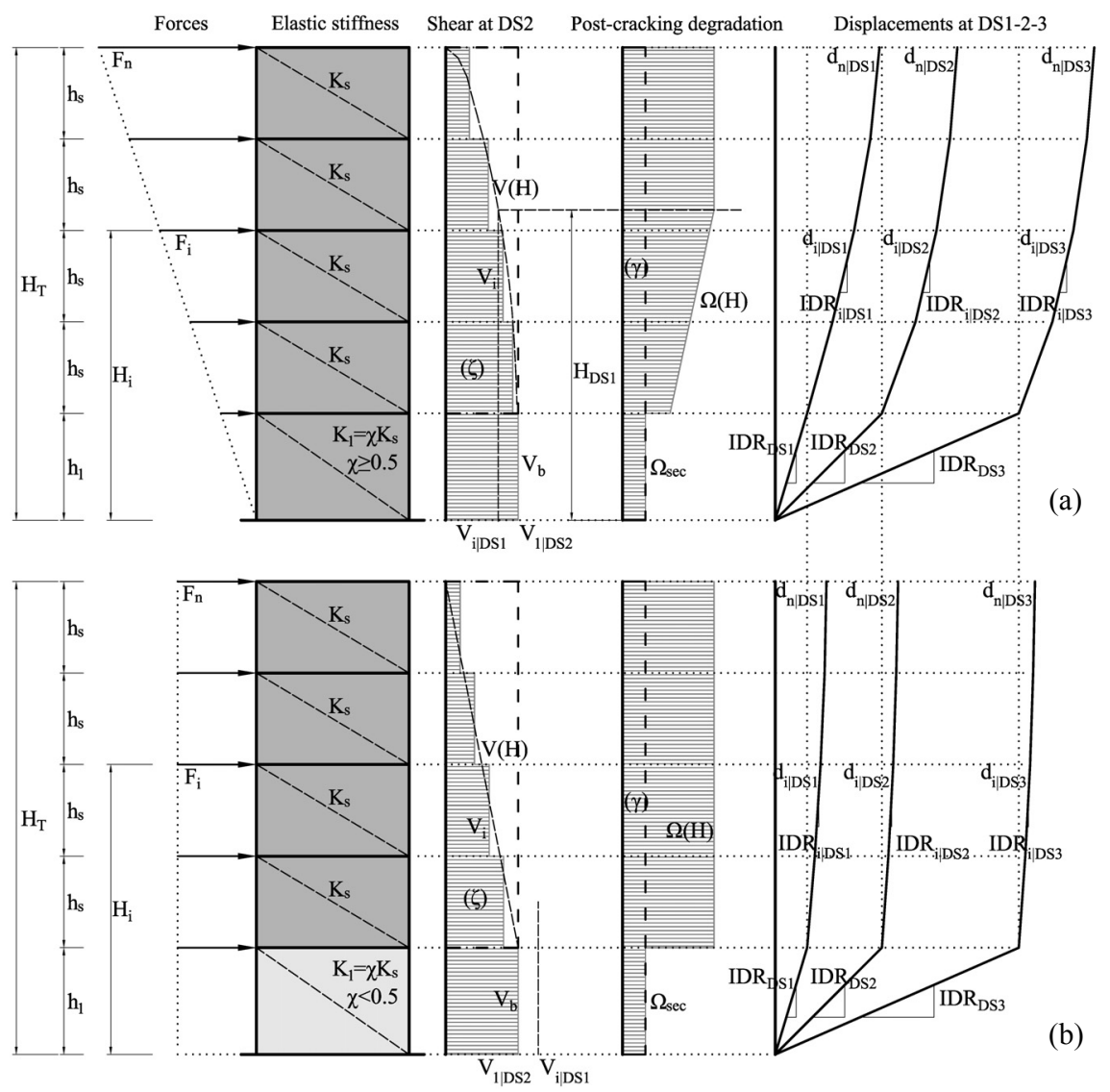

Figure 2: $\quad$ Models adopted for uniformly (a) and non-uniformly (b) infilled frames. Definitions and expressions for variables can be found in the Appendix. 


\subsubsection{Lateral load pattern}

The value of $\chi$ determines the classification of a frame into uniformly or nonuniformly infilled frames. In order to have a better approximation of the two situations, two different load patterns are considered: linear and constant, respectively (Figure 2). The value $\chi=0.5$ represents the boundary between uniformly and non-uniformly infilled frames. This value corresponds approximately to that for which the error respect to the exact results - in terms of first mode participating mass - obtained using both load patterns, become similar.

Consequently, shear forces distributions are obtained for each model (see the Appendix for details). They are parabolic and linear for uniformly and nonuniformly infilled frames, respectively. In the case of uniformly infilled frames, $\zeta$ assumes a value of $2 / 3$; it is equal to the area of the parabola with respect to the circumscribed rectangle in the case of $h_{l}=h_{s}$, while it is some hundredths down for $h_{1}>h_{s}$. In the case of non-uniformly infilled frames, always $\zeta=1 / 2$ (the area of the triangle respect to the circumscribed rectangle).

\subsubsection{Elastic dynamic properties}

Interstorey displacements are obtained through the parameters $h_{1}, h_{s}, \chi$, $\zeta$. Thus, top displacement $\left(d_{n}\right)$ is evaluated as the sum of two contributions, the first of ground storey and the second of all the other storeys. The assumption of equal masses at each storey allows the definition of $\left(\mathrm{m}^{*} / \mathrm{M}\right)$ and $\Gamma$ as functions only of the storey displacements (see the Appendix for details). Table 1 shows the values of $\left(\mathrm{m}^{*} / M\right)$ and $\Gamma$ in the case of equal interstorey heights $\left(h_{l}=h_{s}\right)$. It is worth noting that the values computed are consistent with the assumptions of ASCE [8].

Table 1: $\quad\left(\mathrm{m}^{*} / \mathrm{M}\right)$ and $\Gamma$ for 4 and 8-storey uniformly and non-uniformly infilled frames.

\begin{tabular}{cccccccccc}
\hline & \multicolumn{4}{c}{ Uniformly infilled frames } & \multicolumn{4}{c}{ Non-uniformly infilled frames } \\
\hline$\chi$ & $n$ & $m^{*} / M$ & $\Gamma$ & $\Gamma \cdot m^{*} / M$ & $\chi$ & $n$ & $m^{*} / M$ & $\Gamma$ & $\Gamma \cdot m^{*} / M$ \\
\hline \multirow{2}{*}{1.0} & 4 & 0.71 & 1.25 & 0.89 & \multirow{2}{*}{0.3} & 4 & 0.86 & 1.13 & 0.98 \\
& 8 & 0.67 & 1.28 & 0.85 & & 8 & 0.80 & 1.19 & 0.95 \\
\hline
\end{tabular}

\subsubsection{Elastic fundamental period}

In eqn (3), the elastic fundamental period is expressed in closed-form as function of $n,\left(m^{*} / M\right)$ and $\left(K_{g} / A_{b}\right)$. The last one is obtained as the ratio between base shear force and top displacement, normalized by the building area (see the Appendix for details). Accordingly, the so calculated elastic fundamental period (Figure 3) increases its value with the decreasing of $\chi$, showing a quasi-linear shape when expressed as function of $n$. In the case of $\chi=1$ (uniformly infilled frame), the values of $T_{e l, \text { inf }}$ for different infill ratios are similar to those obtained in (Ricci et al. [5]) using a numerical expression with experimental basis, employed in the previous version of FAST (De Luca et al. [1], Manfredi et al. [2]). 
(a)

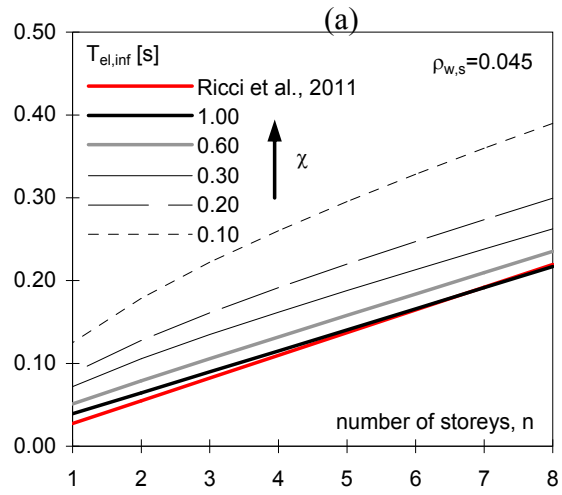

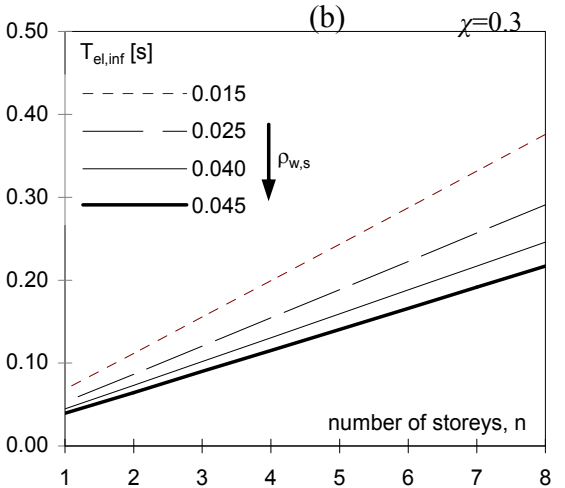

Figure 3: $\quad$ Elastic fundamental period depending on $\chi(\mathrm{a})$ and $\rho_{w, s}$ (b).

\subsubsection{Post-cracking stiffness degradation}

Finally, in order to calculate the factor $\gamma$, it is necessary to evaluate the level of stiffness degradation, if any, of the infills at the upper storeys when the first storey attains the threshold interstorey drift characterizing DS2. It is necessary to identify the specific trend of stiffness degradation attained along the different storeys of the building. In particular, each storey is characterized by an equivalent secant stiffness (beyond cracking) obtained as the product of the elastic one, $K_{i}$, and the corresponding degradation factor $\Omega_{i}$ (see section 2.1.2).

First of all, it is necessary to know which is the shear force that causes the attainment of DS2 threshold at ground floor, and the one that causes the DS1 at any upper storey. In general, shear force can be expressed as a product of the equivalent secant stiffness, $\mathrm{IDR}_{i}$ and $h_{i}$. So, those two specific shear forces can be carried out considering in each case the IDR corresponding to the DS $j$ in the $i^{\text {th }}$ storey, and the corresponding $\Omega_{i}: 1$ and 0.25 for DS1 and DS2, respectively.

Then, the shear force distribution corresponding to the attainment of DS2 at the first storey is built up by increasing homothetically the initial shape (see Figure 2). The infills corresponding to upper storeys having a current shear force higher than that corresponding to the DS1 are supposed to be beyond cracking. Unfortunately, the employment of a discrete expression of storey shears results in a difficult evaluation of the number of storeys belonging to the "cracked part". Thus, a continuous functional expression for shear force distribution, depending on the height and matching with the discrete shape, is assumed. Thus, the "cracked part" of the building is placed below the height at which shear force attains the value corresponding to DS1 drift threshold, called "cracked height".

The analytical expression for the "cracked height" could supply also unreal negative values. It would mean that the shear force necessary to make the upper storeys exceed DS1 is higher than the shear force corresponding to the DS2 in the ground floor. This situation is representative of non-uniformly infilled frames: as the infills ratio is very low at ground floor, quite low shear force makes it attain the DS2, while upper storeys are still characterized by uncracked 
stiffness (see Figure 2). On the other hand, for uniformly infilled frames, a typical value for the relative "cracked height" -normalised to the total one - is approximately 0.65 : two thirds of the height are depicted by a cracked stiffness.

Thus, $\Omega_{i}$ is equal to 1 in the upper "elastic" part or the building, while it is expressed in the "cracked part" as a continuous function inversely proportional to the shear force. Then, $\gamma$ is obtained as a relationship between the areas of the diagram of the degradation function (see Figure 2). Typical values of $\gamma$ are 0.35 and 0.25 for uniformly and non-uniformly infilled frames, respectively.

\section{Application to the 2011 Lorca, Spain, earthquake}

Damage survey data relative to the city of Lorca (Murcia, Spain) and collected after the 2011 earthquake $(M w=5.1)$ are employed as benchmark for testing the methodology described in section 2. Main characteristics of the event can be found in De Luca et al. [1] and Cabañas et al. [9]. In the following, all the parameters governing the generalized FAST methodology are specialized to local construction practice of Murcia region and Spain in general.

\subsection{Real damage scenario}

Damage survey data, classified according to EMS-98 damage scale (Grunthal [10]), are provided in aggregated form (Feriche et al. [11]). Those data have been disaggregated (Figure 4) aimed at accounting for damage data of RC structures only (see De Luca et al. [1] for details). Non-structural damage (DS1, 2 and 3 ) increases with the number of storeys, being the DS2 (cracks in partition and infill walls, according to EMS-98 definition) the median and most frequent DS value. Severe structural damage (DS4 and DS5) is quite limited (8.5\%) and it can be observed that recent codes recommendations resulted in a decrease of its amount. Anyway, structural damage in $\mathrm{RC}$ structures $(\mathrm{DS} \geq 3)$ is higher than that for masonry: $23.5 \%$ versus $19.3 \%$. This trend can be likely caused by the occurrence of pre-emptive brittle failures and soft-storey mechanisms in RC structures, because of lacks in design code prescriptions (De Luca et al. [1]).

\subsection{Common design practice}

Lorca RC building stock is approximately characterized by buildings in the range of 3 and 6 storeys, being $h_{l}=3.50 \mathrm{~m}$ and $h_{s}=3.00 \mathrm{~m}$. RC building stock is constructed mainly after 1974 (De Luca et al. [1], Cabañas et al. [9], Feriche et al. [11]). Thus, most of the RC building stock was realized according to PDS-1 (1974), NCSR-94 (1994) and NCSE-02 (2002) Spanish seismic codes. These codes are characterized by some lacks: they do not provide any quantitative capacity design rule, there is no drift limitation and there is no prevention against the global or local unfavourable influence of the infills. The most common structural solution is: wide beams, slender columns sometimes characterized by highly spaced stirrups, absence of shear walls and often a significant reduction of infills at ground storey. 
Aimed at defining $\chi$ for the case of Lorca, it is necessary to assume the typical values of $\rho_{w, i}$ and $\rho_{w, s}$ for infills and approximate dimensions for ground floor RC columns (see section 2.2.1). The other parameters necessary for generalized FAST implementation are: $m_{r}=0.8 \mathrm{t} / \mathrm{m}^{2}, G_{w}=1350 \mathrm{MPa}$ (CSLLPP [12]), $\tau_{\max }=$ $1.3 \tau_{c r}$ (Fardis [13]), being $\tau_{c r}=0.35 \mathrm{MPa}$ (CSLLPP [12]).

(a)

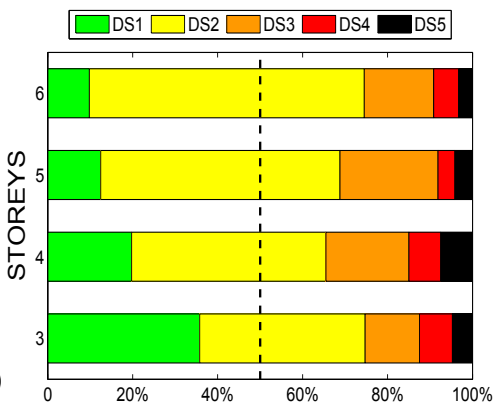

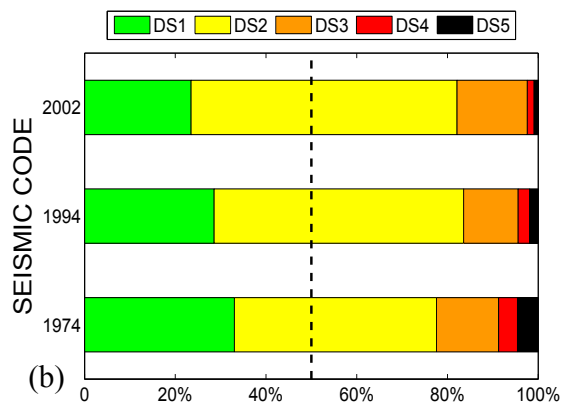

Figure 4: DS for RC buildings by number of storeys (a) and seismic code (b).

\subsubsection{Infills}

Data available in literature (Crowley and Pinho [14]) for infills ratio in residential buildings of Mediterranean area suggest a constant-in-elevation $\rho_{w, i}=2.5 \%$. In order to apply the generalized method, these general data are integrated by an in-field observational analysis, aimed at determining the typical infill ratios in upper storeys and ground floor with a reduction of the amount of infills. In the following some building examples are provided aimed at showing the typical infill amount observed in Lorca RC building stock, later on applied to all the classes of buildings.

In Figure 5, two examples of plan configurations of buildings with commercials at ground floor, located in Lorca, are shown. These examples are meant to show the way in which infill percentage were evaluated on a selected sample of buildings considered to be representative of the whole building stock. Regarding the way of accounting for the infills, there are three hypotheses about their effectiveness, depending on their location respect to the RC frame.

The infills can be divided in: external (ex), which are facades or separation walls thicker than $15 \mathrm{~cm}$, placed into a RC frame; internal aligned $(a l)$, thin walls of usually $10 \mathrm{~cm}$ placed into a RC frame; and internal not aligned (in), that include all the partitions not placed in any RC frame. Usually only $(e x)$ are considered as effective, since the other could not reach the upper slab and are characterized by high uncertainties on their position and characteristics. On the other hand, $(a l)$ in many cases may be as effective as (ex), even in the case in which no beams are located above and simply longitudinal joists close the contour structural frame. Finally, (in) are usually neglected, as they are supposed not to be able to develop post-cracking diagonal-strut behaviour. However, (in) 
can develop their elastic shear resistance ( $\tau_{c r}$ instead of $\tau_{\max }$ ), which could be lower than the demand for any event in a non-uniformly infilled frame (see section 2.2.5). Also, they may influence the value of the elastic period.

According to these observations, three different cases are considered: (1) only the external infills are effective $(e x)$; $(2)$ also the interior aligned do $(e x+a l)$; and (3) that all the infills are effective $(e x+a l+i n)$. Openings and double layers (when present) are considered. For the evaluation of $\rho_{w, i}$, only infills oriented in the considered direction are taken into account. According to results shown in Table 2, it can be observed that hypothesis (1) leads to very low $\rho_{w, i}$ values,
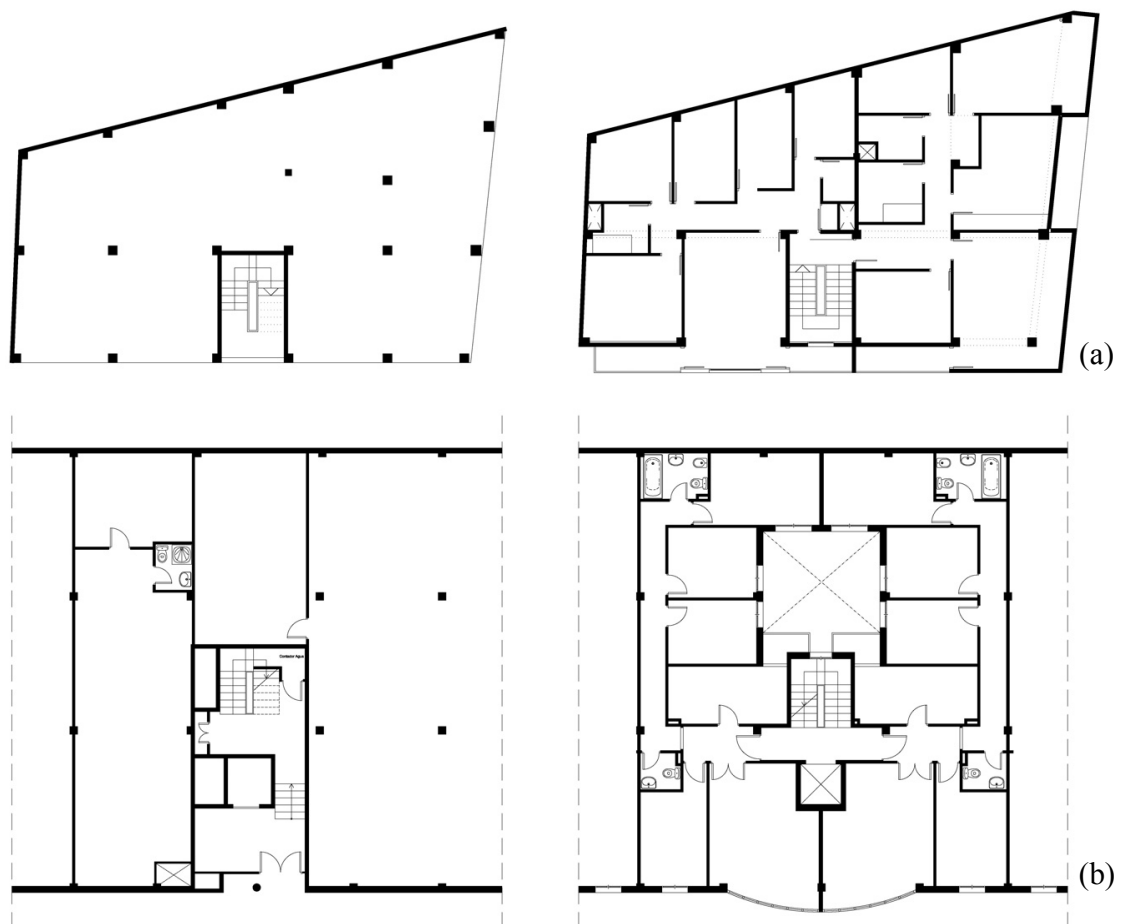

Figure 5: $\quad$ Ground and upper floors of buildings A (a) and building B (b).

Table 2: $\quad$ Infills ratios for buildings $\mathrm{A}$ and $\mathrm{B}$.

\begin{tabular}{cccccccc}
\hline & & \multicolumn{3}{c}{$\rho_{w, 1}[\%]$} & \multicolumn{3}{c}{$\rho_{w, s}[\%]$} \\
\cline { 3 - 8 } Building & Direction & $e x$ & $e x+a l$ & $e x+a l+i n$ & $e x$ & $e x+a l$ & $e x+a l+i n$ \\
\hline \multirow{2}{*}{$\mathrm{A}$} & $\mathrm{X}$ & 1.3 & 1.5 & 1.5 & 2.1 & 2.8 & 4.5 \\
& $\mathrm{Y}$ & 0.8 & 1.4 & 1.4 & 2.1 & 3.1 & 4.6 \\
\hline \multirow{2}{*}{$\mathrm{B}$} & $\mathrm{X}$ & 0.8 & 1.0 & 1.3 & 1.6 & 2.1 & 3.9 \\
& $\mathrm{Y}$ & 1.1 & 1.4 & 1.8 & 1.9 & 2.3 & 3.9 \\
\hline \multirow{2}{*}{} & average & 1.1 & 1.3 & 1.5 & 1.9 & 2.6 & 4.2 \\
& & & & $\rho_{w, 1} / \rho_{w, s}$ & 0.52 & 0.51 & 0.36 \\
\hline
\end{tabular}


while in the case of hypothesis (2) the average value is $2.6 \%$ in upper storeys, consistent with Crowley and Pinho [14], having the ground floor approximately half of the amount. When hypothesis (3) is considered, the amount of upper walls increases to $4.2 \%$ resulting in a ratio of 0.36 between ground and upper storeys.

\subsubsection{RC structure}

RC columns' dimensions have been evaluated according to a lower bound estimation. Maximum value between approximate gravitational and seismic design according to the prescriptions of DA-EHE (CSCAE [15]) Spanish code have been considered. Thus, a simulated design procedure is carried out, considering square columns with tributary area of $15 \mathrm{~m}^{2}$ (based on in-field observations). Typical values of design loads, material properties and reinforcement ratios are considered. Hence, values of $c_{\chi}$ (see section 2.1.2) range between a minimum of $4 \%$ for three storey uniformly infilled buildings designed according to 1974 code and considering hypothesis (3) for infills, and $27 \%$ for six storey non-uniformly infilled buildings designed according 2002 code and considering hypothesis (1) for infills. Furthermore, in upper storeys, even considering only the external infills, $c_{\chi}$ is always lower than $5 \%$; consequently, $\mathrm{RC}$ influence can be always neglected at upper storeys, according to the assumption of the method.

\subsection{Results: predicted damages}

Generalized FAST is applied to the infilled RC-MRF buildings of Lorca, considering 3 to 6 storeys buildings designed according the 1974, 1994 and 2002 Spanish seismic codes. Thus, predicted average DS for each class of building when subjected to the PGA of Lorca earthquake $\left(\mathrm{PGA}_{d}\right)$ is obtained. Six potential representative situations have been studied, corresponding to the three hypotheses made on the evaluation of $\rho_{w, i}$ for uniformly (Figure 6) and nonuniformly infilled (Figure 7) frames. In fact, no information is available about the fraction of each type of building with respect to the total RC building stock. Results shown can be considered as an upper and lower bound estimation of the predicted DS. These results are finally compared with the survey damage data.

In the first rows of Figure 6 and 7, CC and IN2 for the normal (FN) and parallel (FP) direction to the fault of the earthquake are shown. Due to the different corner period of the event in each direction (De Luca et al. [1]), the structures are more resistant in the FP direction. This circumstance, together with the fact that the $\mathrm{PGA}_{\mathrm{d}}$ is bigger in $\mathrm{FN}$, converts it in the relevant direction when comparing the results with the scenario. If comparing uniform's and nonuniform' CC for each hypothesis, it can be observed that there is a reduction of the maximum capacity $C_{s, \max }$ and an increment of the equivalent period $T_{\text {eff,inf }}$ for the non-uniformly infilled frames. In second rows of Figures 6 and 7, thresholds of DS are obtained, showing a substantial reduction of the displacement capacity for the non-uniformly infilled frames, as this is mainly concentrated in the first storey. In third rows of the same figures, predicted DS for every class are presented. In some cases it is not clear the trend depending on the number of 
storeys; the latter is a consequence of the use of the spectra of the recorded FN signal, very sensitive to period variability, instead of smoothed ones.

Results show that the expected lower limit of damage is DS1 (for uniformly infilled frames in the case of hypothesis (3) for the infills) and upper limit is DS3 (for non-uniformly infilled frames in the case of hypothesis (1) for the infills). Expected damage is inversely proportional to the amount of infills considered. As explained in section 3.2.1, the expected damages for both cases (uniformly and non-uniformly infilled frames) may be those intermediate between the results accounting and not accounting for the internal not aligned infills. For uniformly infilled frames, not accounting for internal infills may be a reasonable consideration; otherwise the unrealistic increase of base shear would affect significantly the results.
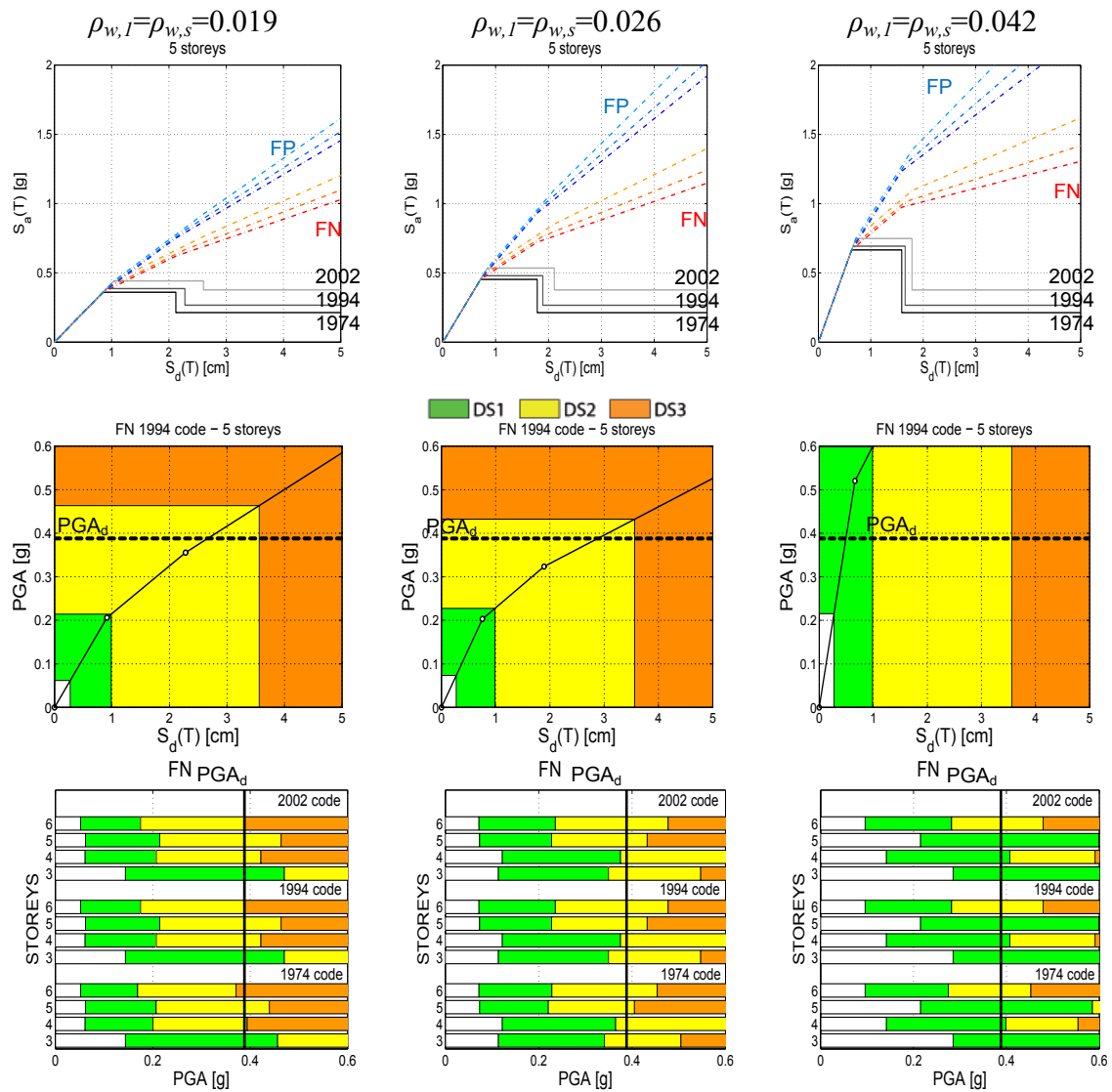

Figure 6: Uniformly infilled frames. Upper row: IN2+CC for 5-storey buildings; medium row: IN2, DS thresholds and predicted DS for $\mathrm{PGA}_{\mathrm{d}}$ for 5-storey-1994-code buildings; lower row: predicted DS for all the classes. All considering three hypothesis of accounting for the infills: $e x\left(1^{\text {st }} \mathrm{col}\right.$.), ex + al ( $2^{\text {nd }} \mathrm{col}$.) and $e x+i n\left(3^{\text {rd }} \mathrm{col}\right.$. $)$. 

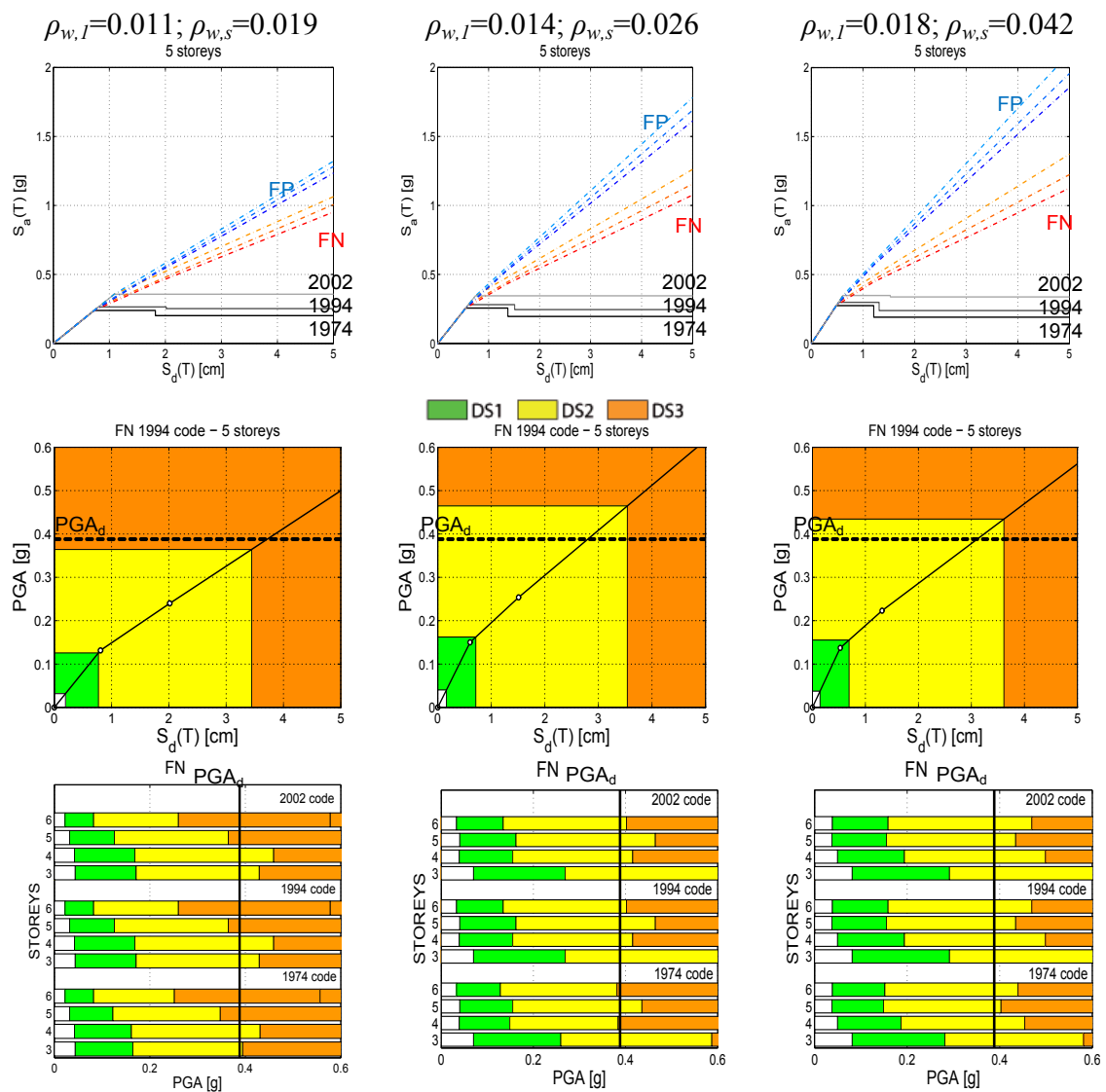

Figure 7: Non-uniformly infilled frames. Upper row: IN2+CC for 5-storey buildings; medium row: IN2, DS thresholds and predicted DS for $\mathrm{PGA}_{\mathrm{d}}$ for 5-storey-1994-code buildings; lower row: predicted DS for all the classes. All considering three hypothesis of accounting for the infills: $e x\left(1^{\text {st }}\right.$ col. $), e x+a l\left(2^{\text {nd }}\right.$ col. $)$ and $e x+i n\left(3^{\text {rd }}\right.$ col. $)$.

However, in the case of non-uniformly infilled frames, as all the upper storeys remain elastic and a small amount of interior infills are located at the ground storey, the approach would be to consider all the walls. Thus, average DS2 can be expected for the RC building stock of Lorca, prediction in accordance with the observed damage (Figure 4).

\section{Conclusion}

A generalized version of FAST vulnerability method for infilled RC-MRF buildings is provided, aimed at including the situations in which a reduction of the amount of infills at ground floor is observed, covering all intermediate 
situations between uniformly and pilotis frames. The theoretical formulation of the method is supported by assumptions based on existing literature. Generalized FAST is applied considering local Spanish construction practice and considering different hypothesis about the effectiveness of the infills depending on their position aimed at a benchmarking application of the method to the case of 2011 Lorca earthquake. Finally, analytical results are compared with observed damage data of this earthquake. The outcome of the comparison emphasizes a fair agreement of analytical results with observed results.

\section{Appendix}

Description and extended formulae corresponding to the parameters presented in Figure 2 and sections 2.2 to 2.2 .5 are reported herein. They refer to parameters required for the construction of the deformed shape and for obtaining the elastic period for both cases: uniformly and non-uniformly infilled frames. The specific case of equal heights $\left(h_{I}=h_{s}\right)$ can be reproduced by substituting $H_{i}$ by $i$ in all the equations.

\begin{tabular}{|c|c|c|c|}
\hline$F_{i}$, & $\begin{array}{l}\text { Force applied at the } i^{\text {th }} \text { storey } \\
\text { Parameters assuming increasing }\end{array}$ & $\begin{array}{l}I D R_{D S j} \\
H\end{array}$ & $\begin{array}{l}\text { Interstorey drift causing } \mathrm{DS} j \\
\text { Height to any part of the frame }\end{array}$ \\
\hline & & & e frame \\
\hline & Height to the $i^{\text {th }}$ storey & $V(H)$ & sexpression of shear \\
\hline & Shear force at the $t^{\text {th }}$ storey & & forces \\
\hline & Elastic stiffness at ground stor & $V_{b}$ & ntinuous \\
\hline & Elastic stiffness at upper storey & & \\
\hline$R_{i}$ & Interstorey drift at the $i^{\text {th }}$ storey & $H_{D S I}$ & "Cracked height" \\
\hline & Shear force causing DS $j$ at the $i^{\text {th }}$ & $\Omega(H)$ & Degradation function \\
\hline
\end{tabular}
storey

$$
\begin{gathered}
F_{i}=\left\{\begin{array}{l}
a H_{i}, \chi \geq 0.5 \\
a^{\prime}, \chi<0.5
\end{array}\right\} \Rightarrow V_{i}=\left\{\begin{array}{cc}
a \sum_{i}^{n} H_{i} & , \chi \geq 0.5 \\
a^{\prime}(n+1-i), \chi<0.5
\end{array}\right\} \Rightarrow V_{(i=1)}=V_{1}=\left\{\begin{array}{c}
a \sum_{1}^{n} H_{i}, \chi \geq 0.5 \\
n a^{\prime} \quad, \chi<0.5
\end{array}\right\} \\
\zeta=\left\{\begin{array}{c}
\frac{\sum_{2}^{n} \sum_{i}^{n} H_{i}}{(n-1) \sum_{1}^{n} H_{i}} \approx \frac{2}{3}, \chi \geq 0.5 \\
\frac{\sum_{1}^{n-1} i}{\frac{n}{n(n-1)}=\frac{1}{2}} \quad, \chi<0.5
\end{array}\right\} ; \quad\left(K_{g} / A_{b}\right)=\frac{G_{w} \rho_{w, s}}{h_{s}\left[\frac{1}{\chi}+\zeta(n-1)\right]}
\end{gathered}
$$




$$
\begin{aligned}
& d_{n}=\frac{V_{1}}{K_{s}}\left[\frac{1}{\chi}+\zeta(n-1)\right] ;\left(\frac{m^{*}}{M}\right)=\left\{\begin{array}{l}
\frac{\frac{n}{\chi} \sum_{1}^{n} H_{i}+\sum_{2}^{n}\left[(n+1-i) \sum_{i}^{n} H_{i}\right]}{n\left[\frac{1}{\chi}+\zeta(n-1)\right] \sum_{1}^{n} H_{i}}, \chi \geq 0.5 \\
\frac{\frac{n^{2}}{\chi}+\sum_{1}^{n-1} i^{2}}{n^{2}\left[\frac{1}{\chi}+\frac{1}{2}(n-1)\right]}
\end{array}, \chi<0.5\right\} \\
& \Gamma=\left\{\begin{array}{l}
\frac{\sum_{1}^{n} H_{i}\left[\frac{1}{\chi}+\zeta(n-1)\right]\left[\frac{n \sum_{1}^{n} H_{i}}{\chi}+\sum_{2}^{n}\left[(n+1-i) \sum_{i}^{n} H_{i}\right]\right]}{\frac{\left(\sum_{1}^{n} H_{i}\right)^{2}}{\chi^{2}}+\sum_{2}^{n}\left[\frac{\sum_{1}^{n} H_{i}}{\chi}+(i-1) \sum_{1}^{n} H_{i}-\sum_{2}^{i} \sum_{1}^{j-1} H_{j}\right]^{2}}, \chi \geq 0.5 \\
\frac{n\left[\frac{1}{\chi}+\frac{1}{2}(n-1)\right]\left[\frac{n^{2}}{\chi}+\sum_{2}^{n}(n+1-i)^{2}\right]}{\frac{n^{2}}{\chi^{2}}+\sum_{2}^{n}\left[\frac{n}{\chi}+(i-1)(n+1)-\sum_{2}^{i} i\right]^{2}}, \chi<0.5
\end{array}\right\} \\
& I D R_{i}=\frac{V_{i}}{K_{i} h_{i}} \Rightarrow\left\{\begin{array}{l}
V_{i \mid D S 1}=I D R_{D S 1} K_{s} h_{s} \\
V_{1 \mid D S 2}=I D R_{D S 2} \Omega_{\mathrm{sec}} K_{1} h_{1}
\end{array}\right\} \\
& V(H)=\left\{\begin{array}{cc}
\frac{a}{2}\left(H_{T}{ }^{2}-H^{2}\right) & , \chi \geq 0.5 \\
a^{\prime}\left(H_{T}-H\right) & , \chi<0.5
\end{array}\right\} \Rightarrow V(0)=V_{b}=\left\{\begin{array}{c}
\frac{a H_{T}{ }^{2}}{2}, \chi \geq 0.5 \\
a^{\prime} H_{T}, \chi<0.5
\end{array}\right\}
\end{aligned}
$$

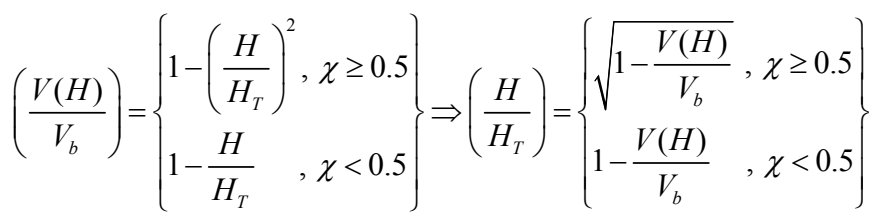

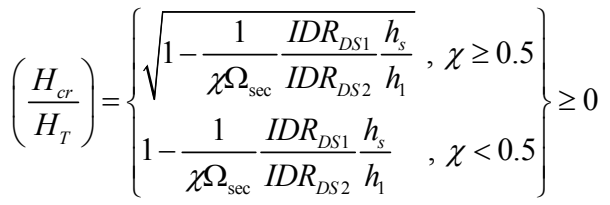




$$
\Omega(H)=\left\{\begin{array}{ll}
\Omega_{\mathrm{sec}}+H_{T} \cdot H \frac{1-\Omega_{\mathrm{sec}}}{\left(H_{c r} / H_{T}\right)}, & \mathrm{H}<H_{D S 1} \\
1 & , H \geq H_{D S 1}
\end{array}\right\} ; \quad \gamma=\frac{2 \Omega_{\mathrm{sec}}}{\left(\frac{H_{c r}}{H_{T}}\right)\left(\Omega_{\mathrm{sec}}-1\right)+2} \geq \Omega_{\mathrm{sec}}
$$

\section{References}

[1] De Luca F, Verderame GM, Gómez-Martínez F, Pérez-García A. The structural role played by masonry infills on RC building performances after the 2011 Lorca, Spain, earthquake. Bull Earthq Eng, DOI 10.1007/s10518-013-9500-1. 2013.

[2] Manfredi G, Verderame GM, Prota A, Ricci P, De Luca F. 2012 Emilia earthquake, Italy: Reinforced Concrete buildings response. Bull Earthq Eng. DOI 10.1007/s10518-013-9512-x. 2012.

[3] Dolšek M, Fajfar P. Simplified non-linear seismic analysis of infilled reinforced concrete frames. Earthq Eng Struct Dyn 34,49-66. 2005.

[4] Manfredi G, Ricci P, Verderame GM. Influence of Infill Panels and Their Distribution on Seismic Behavior of Existing Reinforced Concrete Buildings. The Open Construction and Building Technology Journal 6, (Suppl 1-M1). 2012.

[5] Ricci P, Verderame GM, Manfredi G. Analytical investigation of elastic period of infilled RC MRF buildings. Eng Struct 33(2), 308-319. 2011.

[6] Galasso C, Cosenza E, Maddaloni G. Statistical analysis of reinforcing steel properties for seismic design of RC structures. Proceedings of the 14th European Conference on Earthquake Engineering, Ohrid, Macedonia. 2011.

[7] Colangelo F. A simple model to include fuzziness in the seismic fragility curve and relevant effect compared with randomness. Earthq Eng Struct Dyn 41, 969-986. 2012.

[8] American Society of Civil Engineers (ASCE). Seismic Rehabilitation of Existing Buildings, ASCE/SEI 41-06, Reston, Virginia. 2007.

[9] Cabañas L, Carreño E, Izquierdo A, Martínez JM, Capote R, Martínez J, Benito B, Gaspar J, Rivas A, García J, Pérez R, Rodríguez MA, Murphy P. Informe del sismo de Lorca del 11 de mayo de 2011. 2011.

[10] Grunthal G (ed). European macroseismic scale 1998. Cahiers du Centre Europeen de Geodynamique et de Seismologie, 7, Luxembourg. 1998.

[11] Feriche M, Vidal F, Alguacil G, Navarro M, Aranda C. Vulnerabilidad y daño en el terremoto de Lorca de 2011. $7^{\mathrm{a}}$ Asamblea hispano-portuguesa de Geodesia y Geofísica. San Sebastián, España. 2012.

[12] CSLLPP. Istruzioni per l'applicazione delle norme tecniche delle costruzioni. Gazzetta Ufficiale della Repubblica Italiana, 47 (in Italian). 2009. 
[13] Fardis MN. Experimental and numerical investigations on the seismic response of RC infilled frames and recommendations for code provisions. Report ECOEST-PREC8 No 6. 1997.

[14] Crowley H, Pinho R. Revisiting Eurocode 8 formulae for periods of vibration and their employment in linear seismic analysis. Earthq Eng Struct Dyn 39(2), 223-235. 2010.

[15] CSCAE. Documento de aplicación de la EHE-08 a edificación: DA-EHE. Consejo Superior de Colegios de Arquitectos de España. Madrid. 2009. 